\title{
Asymmetric 1,3-Dipolar Cycloadditons of Stabilized Azomethine Ylides with Nitroalkenes
}

\author{
Carmen Nájera* and José M. Sansano $\Omega$
}

Departamento de Química Orgánica and Instituto de Síntesis Orgánica (ISO). Universidad de Alicante, E-03080-
Alicante, Spain

\begin{abstract}
This review highlights the biological importance of many polysubstituted nitro-prolines and -pyrrolidines. Their preparation using asymmetric 1,3-dipolar cycloadditions of azomethine ylides with nitroalkenes using diastereoselective and enantioselective strategies is described remarking the scope and main features of each one.
\end{abstract}

Keywords: Antitumoral, asymmetric synthesis, catalysis, cycloaddition, metal, organocatalyst.

\section{INTRODUCTION}

The relationship between nitrocompounds and explosive agents have been established for ages but during the last two decades many contributions demonstrated the potential interest of those molecules bearing a nitro functional group. From the organic synthetic point of view the utility of these compounds atomic arrangement as building blocks has broadened on the basis of two main features of the nitro-functional group: firstly, its activating effect promotes numerous series of reactions (Henry, Nef, Michael-type additions, cycloadditions, radical denitration, heterocycle formations, etc.), and secondly, its facile transformation into various functional groups [1]. The potential biological activity of the family of nitrocompounds is very interesting, for example, some nitroheterocycles are antibiotic drugs [2], other are genotoxic and several nitrocompounds appear to be well tolerated toxicologically and have enjoyed diverse uses in industrial, cosmetic, and agricultural applications [3]. We have focused our attention on chiral molecules 1-5 (Fig. 1), which have a common structural proline derivative core. Molecules $\mathbf{1}$ are important inhibitors of $\alpha_{4} \beta_{1}$-integrin-mediated hepatic melanoma and in a murine model of colon carcinoma metastasis, as well as potent antiadhesive properties in several cancer cell lines $[4,5]$. Bicyclic heterocycles $\mathbf{2}$, containing atropane scaffold have been found as novel inhibitors of hedgehog signaling. The deregulation of hedgehog signaling is directly involved in the development of skin cancer [6]. The bioprospection of spirooxindoles 3 has been analyzed following the zebrafish embryo model determining. The $\mathrm{LC}_{50}$ values indicated elevated mortality of embryos in several tests [7]. Hybrid molecules $\mathbf{4}$ with benzopyran skeleton were successfully tested as antimycobacterials against M.tub osis H37Rv strain [8]. Finally, the most simple prolit ro-5 $_{0}$ have been recently used as chiral organocatalysts in aldol reactions obtaining good to excellent diastereoselections and

*Address correspondence to this author at the Departamento de Química Orgánica and Instituto de Síntesis Orgánica (ISO). Universidad de Alicante, E-03080-Alicante, Spain; Tel: +34-965903549; Fax: +34-965903549;

E-mail:cnajera@ua.es; jmsansano@ua.es high enantiomeric ratios [9]. These applications and properties of the mentioned compounds represent a small part of the enormous interest of prolines and pyrrolidines in many scientific areas [10-12].

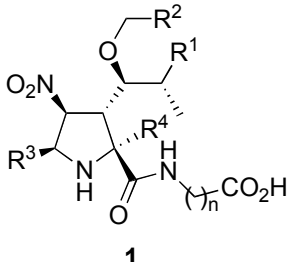

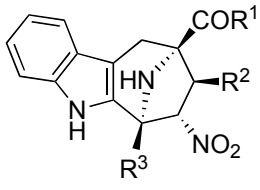

2

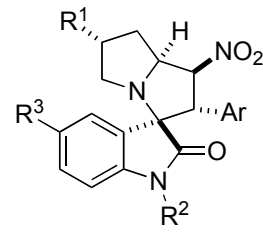

3

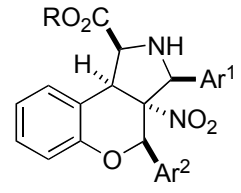<smiles>[Y10][C@H]1[C@@H](C(C)=O)N[C@@H]([AlH2])[C@@H]1[N+](=O)[O-]</smiles>

Fig. (1).

All this series of compounds $\mathbf{C}$, bearing attached a nitro group, can be prepared in a straightforward manner employing asymmetric 1,3-dipolar cycloadditions (1,3-DC) between stabilized azomethine ylides generated from imino esters A or even its corresponding iminium salt $\mathbf{A}^{\mathbf{\prime}}$ and nitroalkenes $\mathbf{B}$ [13-20] employing very mild reaction conditions according to the retrosynthetic pathway shown in (Scheme 1). The most employed 1,3-dipole in the literature is the azomethine ylide [21-27], which can be generated from diverse routes [22]. But the synthesis of the intermediate metalloazomethine ylides acquired more relevance when it was noticed that a high control of the geometry of the intermediate dipole occurred by the metal cation. Firstly, the diastereoselection was excellent [22] and later on, in 2002, a high enantioselection was achieved in the first enantioselective catalyzed processes [28-30]. This last reaction allows creating up to four stereogenic centers in just only one synthetic operation.

The following sections concern the recent advances in the two most frequently employed asymmetric approaches for the synthesis of these nitro-derived prolinates by diastereoselective or enantioselective catalyzed processes. 


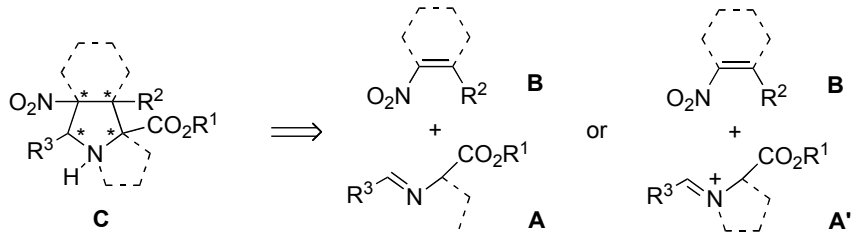

Scheme 1

\section{DIASTEREOSELECTIVE APPROACHES}

Despite publishing many diasteresoselective 1,3-DC between azomethine ylides and alkenes, a few number of contributions employed nitroolefins as dipolarophile [22, 27]. Such as it was detailed in the previous section, enantiomerically enriched polysubstituted pyrrolydines $\mathbf{1}$, with a potent antimetastatic activity, were prepared in twelve preparative steps, the formal [3+2] cycloaddition between imines 6 and nitroalkenes 2 ing the key step (Scheme 2) [4, 5]. The reaction of the silver metallodipole -generated from 6, AgOAc (10 $\mathrm{mol} \%)$ and triethylamine- was completely diastereoselective in most of the examples reported (up to $>99: 1 d r$ ) including aliphatic aldimines $\left(\mathrm{R}^{3}=\right.$ alkyl). Intermediate proline methyl ester derivatives endo-8 were always isolated as major diastereoisomer [31]. Compound 1a produces the highest antimetastatic activity on male C57BL/6J mice by measuring the inhibition of adhesion between hepatic sinusoidal endothelial (HSE) cells and B16 melanoma cells.
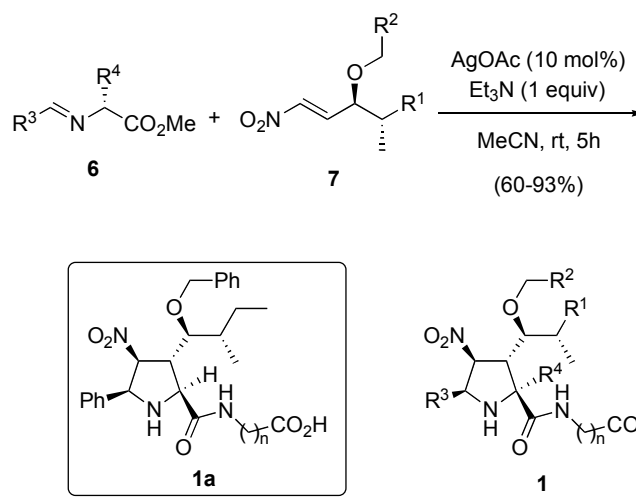

$(60-93 \%)$

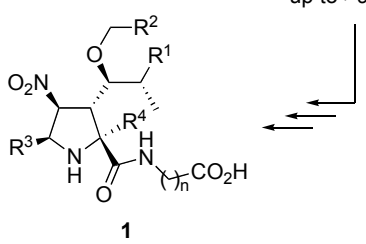

Scheme 2.

A variety of highly functionalized $\beta$-lactam substituted pyrroloisoquinoline and indolizinoindole system was reported. On it, the combination of diastereoselective 1,3-DC involving stabilized azomethine ylides derived from imino esters $\mathbf{9}$ and $\beta$-nitrostyrenes $\mathbf{1 0}$ together with a PictetSpengler cyclization yas successfully implemented. The intermediate cycloatendo-11 was obtained by intermediacy of AgOAc (1 equiv) and triethylamine. The conversions were moderate giving yields ranging between $30-45 \%$, and the $d r$ were very high (up to $>99: 1 d r$ ) (Scheme 3). The main goal of the synthesis of final skeletons $\mathbf{1 2}$ was their pharmaceutical interest as antiarthritic, antiasthmatic and antiallergenic drugs via inhibition of the production of both prostaglandin E2 and intracellular phospholipase A2 [32].

During the synthesis of $\alpha, \gamma$-diaminobu acids (DABAs) 19, a series of non proteinogenic amino acids with interesting nutritional, chemical and biomedical properties, optically active polysubstituted pyrrolidines $\mathbf{2 0}$ were identi- fied as secondary products when the reaction of oxazinones 13 and 14 were deprotonated with LDA, at $-78^{\circ} \mathrm{C}$ in the presence of $\mathrm{Ti}\left(\mathrm{OPr}^{\mathrm{i}}\right)_{4}$, and treated with aliphatic nitroalkenes $10(\mathrm{R}=$ alkyl) (Scheme 4). This reaction afforded diastereoselectively Michael adducts 16 or 18, respectively. Nitrostyrenes 10 gave very clean crude products 15 or 17 and no cycloaddition products were detected. Several attempts to obtain pyrrolidines $\mathbf{2 0}$ were unsuccessfully carried out starting from 13 and 14. The presumably non-reactive imino group of these oxazinones and 15-18 only could be activated by $\mathrm{Cu}(\mathrm{OTf})_{2}$ or by AgOTf as Lewis acids once the Michael adduct (for example 18) was completely formed. This second step, involving a final metal-catalyzed intramolecular Mannich-type reaction, was completed in almost quantitative yield and excellent diastereoselectivity $(>99: 1 d r)$ (Scheme 4) [33].

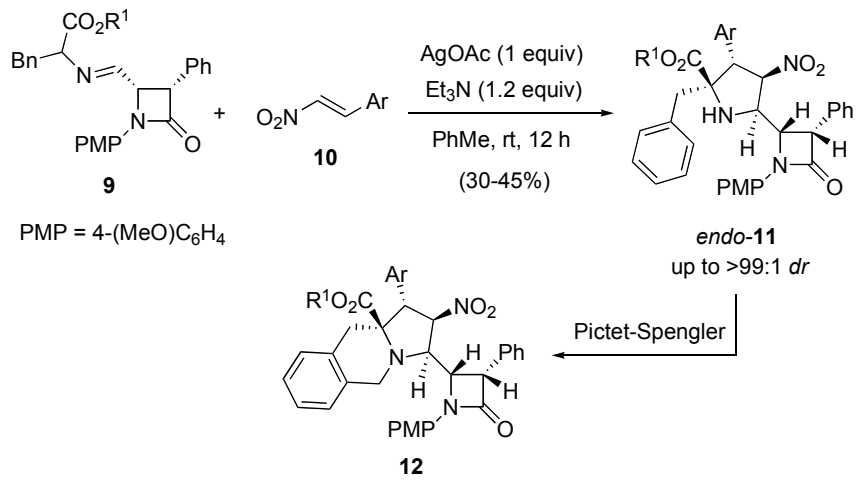

Scheme 3 .

Compounds 5a $\left[\mathrm{Ar}^{1}=\right.$ (diphenylphosphino)ferrocenyl; $\left.\mathrm{Ar}^{2}=\mathrm{Ph}\right]$ and the $\mathrm{N}$-methylated analogue 22 were diastereoselectively prepared taking advantage of the planar chirality of the ferrocenyl scaffold 21. The thermal 1,3-DC via iminium salt between sarcosine methyl ester hydrochloride, aldehyde 21 and nitrostyrene $10(\mathrm{R}=\mathrm{Ph})$ in refluxing toluene afforded, in moderate chemical yield (52\%) and excellent endo-trans-diastereoselection $(>99: 1)$ enantiomerically enriched nitroproline 22 (Scheme 5). The absolute stereochemistry of this molecule $\mathbf{2 2}$ was not frequently found in the literature, and some stereoelectonic effects can justify the presence of this product at the end of the reaction. The multicomponent reaction employing $\mathbf{2 1}$ and glycine methyl ester hydrochloride was not profitable and the imino ester $\mathbf{6}\left[\mathrm{R}^{3}=\right.$ (diphenylphosphino)ferrocenyl; $\mathrm{R}^{4}=\mathrm{H}$ ] was prepared and allowed to react with nitrostyrene in the presence of $\mathrm{LiBr}$ in THF. Compound endo-cis-5a $\left[\mathrm{Ar}^{1}=\right.$ (diphenylphosphino) ferrocenyl; $\mathrm{Ar}^{2}=\mathrm{Ph}$ ] was achieved as sole diastereoisomer in 66\% yield (Scheme 5). Both molecules endo-trans-22 and endo-cis-5a were immediately tested as chiral ligands in combination with copper(I) salts in the enantioselective catalytic 1,3-DC of imino esters 6 with various dipolarophiles (including nitroalkenes) yielding cycloadducts in very good yields and good enantioselections (see, Scheme 8) [9].

In general, the synthesis of compounds 5 were previously described using non-asymmetric procedures starting from the corresponding imino ester $\mathbf{6}$ and nitroalkenes $\mathbf{1 0}$ in order to study the origin of the metal effect $\left(\mathrm{LiClO}_{4}\right.$ or $\left.\mathrm{AgOAc}\right)$ on the stereochemical outcome discovering that the reaction occurred through a two step mechanism [34, 35], and the 


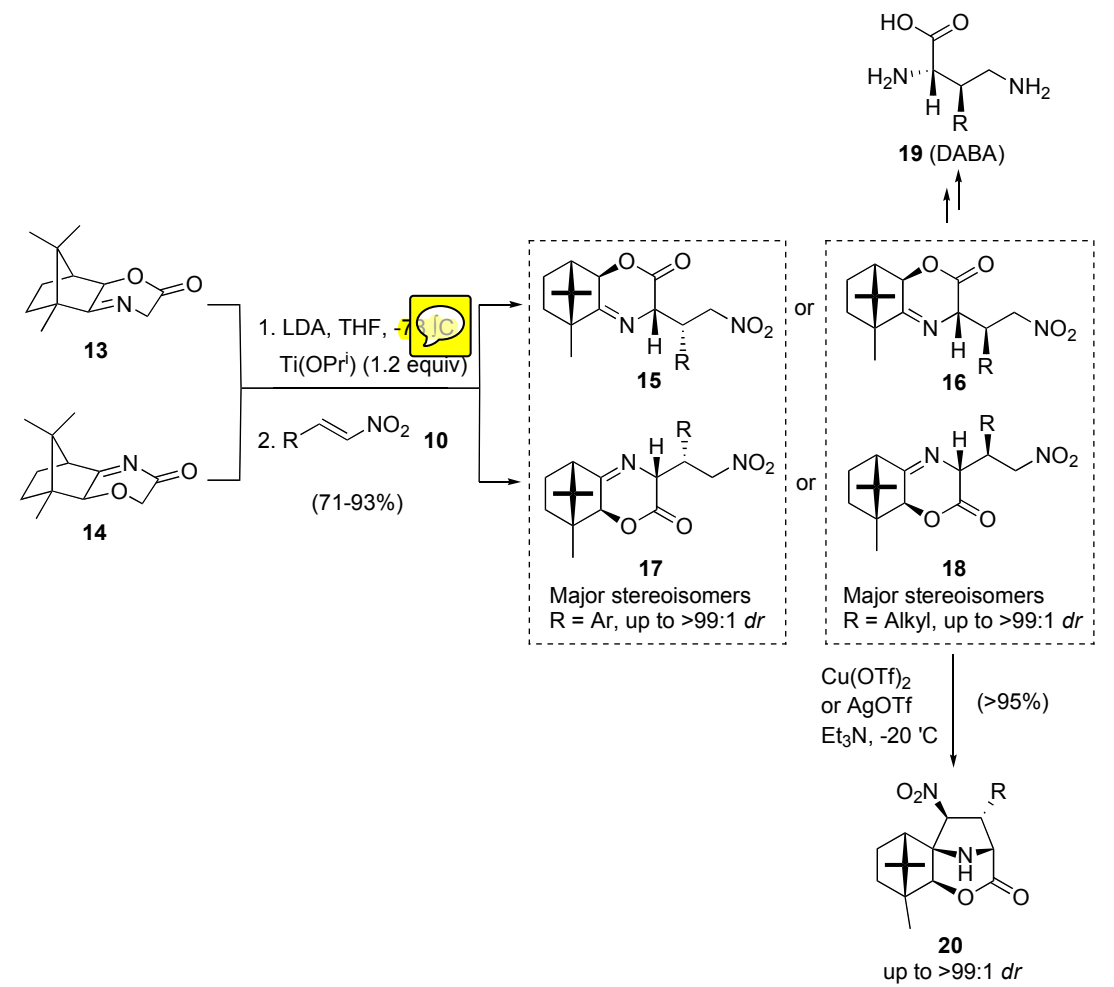

Scheme 4.

scope of the reaction employing different dipolarophiles [36]. In addition, analogous multicomponent reactions have been optimized between azomethine ylides and nitroalkenes $\mathbf{1 0}$ in the presence of lithium [8], or silver [37] salts and also in the absence of a Lewis acid when thermal processes [7] or dialkyl $\alpha$-aminomalonates were used [38-41]. Very recently, the use of 3-nitro-2-trihalomethyl- $2 \mathrm{H}$-chromenes, including 2-unsubstituted derivatives, in 1,3-DC of non-stabilized azomethine ylides allowed the construction of biologically interesting 1-benzopyrano[3,4-c]pyrrolidines trough a multicomponent process [42].

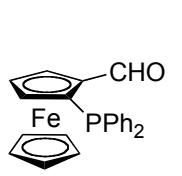

21

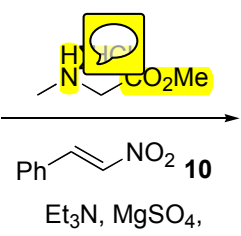

$\mathrm{PhMe}$, reflux

$(56 \%)$

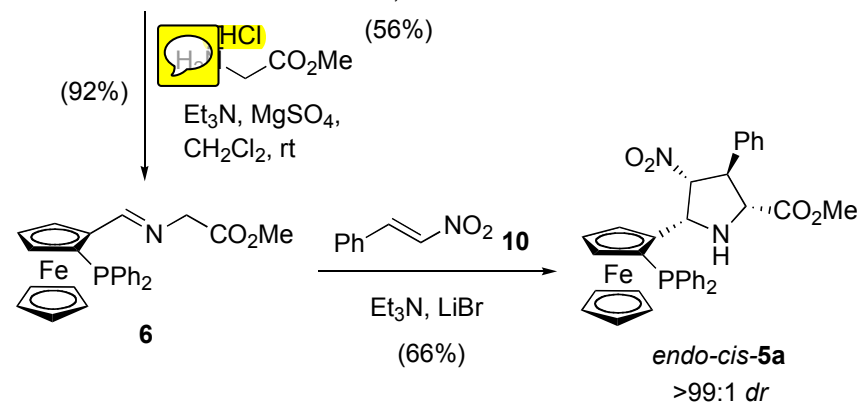

Scheme 5.

\section{ENANTIOSELECTIVE APPROACHES}

Such as it was mentioned before, since 2002 many contributions employing chiral Lewis acids or chiral organocatalysts have been compiled in the literature [13-20]. The number of catalysts and their efficiency contribute to the preparation of multiple and sophisticated molecules with well defined absolute configuration. In general, a wide variety of dipolarophiles have been tested but nitroalkenes, due to their especial coordination ability to the catalyst, offered very interesting diastereoselections. In (Sc e 6) the general enantioselective process is shown. The main activation of 1,3-dipole precursor occurs when a Lewis acid $\left(\mathbf{M} \mathbf{L}_{\mathbf{n}}{ }^{*}\right)$ is employed ensuring a high rigidity of the resulting metallodipole $\mathbf{F}$, however, hydrogen bonding (single or multiple) is the main existing interaction $\mathbf{G}$ during the activation of the nitroalkene (dipolarophile) by the chiral organocatalyst $(\mathbf{L} * \mathbf{H})$.

\subsection{Chiral Copper Complexes as Catalysts}

Chiral copper complexes have been tested in multiple 1,3-DC employing different dipolarophiles [43-49]. They are now the most appropriate catalysts for promoting 1,3-DC between azomethine ylides derived from imino esters $\mathbf{6}$ and nitroalkenes 10 (Scheme 7). Copper(I) and copper(II) salts have been used as metal center so they will be discussed in this Section.

( $\mathrm{F}$ ) contains the bidentate or multidentate chiral ligands employed with copper(I) salts in the catalytic enantioselective 1,3-DC.

It is remarkable the presence of polysubstituted prolines endo-5a and 22 as chiral ligands (Fig. 2), which chelated 
efficiently $\mathrm{Cu}(\mathrm{MeCN})_{4} \mathrm{PF}_{6}$, in THF. It seems that an autocatalytic process is involved in this transformation. These two catalvtic complexes were essayed in the reaction shown in (Sch 8) employing a $5 \mathrm{~mol} \%$ of catalyst loading and triethylamme as base $(5 \mathrm{~mol} \%)$. Under these reaction conditions, endo-5a $\cdot \mathrm{Cu}(\mathrm{MeCN})_{4} \mathrm{PF}_{6}$ afforded exo-cycloadducts 5 in good yield (83-90\%), and both high diastereo- (up to 96:4 $d r)$ and enantioselectivities $(95->99 \% e e)$ when the reaction was performed at $-20{ }^{\circ} \mathrm{C}$. However, $22 \cdot \mathrm{Cu}(\mathrm{MeCN})_{4} \mathrm{PF}_{6}$ chiral complex gave the opposite diastereoisomer endo-5 in good yield (79-85\%), and not with so high diastereo- (up to $96: 4$ $d r)$ and enantioselectivities $(92-94 \% e e)$ when the reaction was performed at $-80{ }^{\circ} \mathrm{C}$ (Scheme 8) [9]. This is a clear example of fine tuning catalyst in order to obtain different stereoisomers maintaining a high efficiency of the processes.

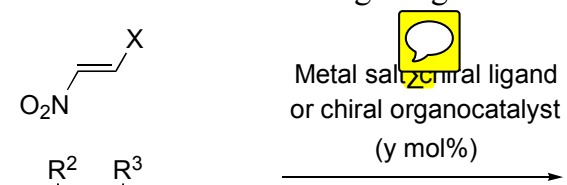

$\overbrace{\mathrm{D}}^{\mathrm{R}^{2}} \overbrace{\mathrm{CO}_{2} \mathrm{R}^{4}}^{\mathrm{R}^{3}}$

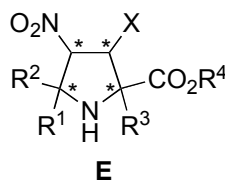

E<smiles>[R]C([O-])=[Y10]([O-])[N+]([NH2+])=C([R])[R]</smiles><smiles>[X]C=C[N+]1=[O+][CH][CH]CC1</smiles>

\section{Scheme 6.}

In this work, ONIOM computational studies were performed. Although it is known that the reaction mechanism involving metallodipoles is stepwise, the first step is responsible for the high stereocontrol observed. The nitro group coordinated $\mathbf{5 a} \cdot \mathrm{Cu}(\mathrm{MeCN})_{4} \mathrm{PF}_{6}$ complex because the nitrogen atom of the pyrrolidine did not interact with the metal centre. This allowed the blockage of one of the two prochiral faces of the dipole favoring the mentioned endo-cycloadduct 5. However, this coordination of the nitro group was not available due to the coordination of the nitrogen atom of the pyrrolidine ring furnishing the exo-cycloadduct 5 [9].

Versatile Fesulphos ligand 23 (3 mol\%) (Fig. 2) and $\mathrm{Cu}(\mathrm{MeCN})_{4} \mathrm{ClO}_{4}(3 \mathrm{~mol} \%)$ as catalytic mixture was employed in the reaction of $\beta$-nitrostyrene $\mathbf{1 0}\left(\mathrm{R}^{1}=\mathrm{Ph}\right)$ and methyl benzylideneaminoglycinate $6\left(\mathrm{R}^{3}=\mathrm{Ph}, \mathrm{R}^{4}=\mathrm{H}, \mathrm{R}^{5}=\right.$ $\mathrm{Me})$ with triethylamine as base $(18 \mathrm{~mol} \%)$ in dichloromethane at $-10^{\circ} \mathrm{C}$. The corresponding exo-cycloadduct 5 was isolated as major diastereoisomer $(95: 5 d r)$ in moderate yield $(61 \%)$ and high enantioselection $(94 \%$ ee) following the general reaction shown in (Scheme 7) $[50,51]$.

Fesulphos $23 \cdot \mathrm{Cu}(\mathrm{MeCN})_{4} \mathrm{PF}_{6}(5 \mathrm{~mol} \%)$ was employed as well in the enantioselective 1,3-DC between a non- conventional dipole precursor derived from tryptophan $\mathbf{3 1}$ and $\beta$-nitrostyrenes $1 \cap 6]$. The exo-adducts 2 were diastereoselectively obtained (up to $>20: 1 d r$ ) using DBU as base $(50 \mathrm{~mol} \%)$ in DCM at $-20{ }^{\circ} \mathrm{C}$. Chemical yields were good $(66-92 \%)$ and the enantioselections elevated (up to 96\% ee) (Scheme 9). T tropane scaffolds have been found as novel intrintors of hedgehog signaling valuable for the identification of tumor cells such as it was previously mentioned.

Ferrocenyl-oxazoline chiral ligands 24 (11 mol\%) (Fig. 2) were selected to catalyze, together to $\mathrm{CuClO}_{4}(10 \mathrm{~mol} \%)$ the reaction shown (1) Scheme 7). Besides, the optimized reaction conditions itruded $\mathrm{KOBu}^{\mathrm{t}}(10 \mathrm{~mol} \%)$, THF as solvent, $4 \AA \mathrm{MS}$, and $0{ }^{\circ} \mathrm{C}$. Catalyst $\mathbf{2 4 a} \cdot \mathrm{CuClO}_{4}$ afforded almost exclusively in all of examples the cycloadductexo-5 (up to $>99: 1 d r)$ in high chemical yields (73-97\%) and high enantioselections $(92-99 \%$ ee). However, the endo-selectivity of products 5 was achieved (up to 89:11 $d r$ ), in very high yields (79-98\%) and interesting enantioselections (92-98\%) just by employing catalyst $\mathbf{2 4 b} \cdot \mathrm{CuClO}_{4}$. This behavior can be considered as an exceptional example of how ligands can finetune the stereoselectivity in asymmetric catalysis by varying their electronic properties. Computational (DFT) and experimental studies confirm a two-stepwise mechanism and justified the observed enantio- and diastereoselection for each catalytic system [52].

A non-common 1,3-dipole precursor was originally prepared in situ starting from imine $\mathbf{3 2}$ and further allowed to react with several dipolarophiles, $\beta$-nitrostyrene $\mathbf{1 0}\left(\mathrm{R}^{1}=\mathrm{Ph}\right)$ being one of them (Scheme 10). The catalytic system comprised bident (Fig. 2) and $\mathrm{Cu}(\mathrm{MeCN})_{4} \mathrm{PF}_{6}(\mathrm{IO} \mathrm{mol} \%)$ and the reaction performed in DCM as solvent and triethylamine $(15 \mathrm{~mol} \%)$ as added base at room temperature. The regioselectivity of the cycloaddition is directed by the electronic charge of the dipole at the $\gamma$ position, which seemed much more stabilized for triggering the cycloaddition. Chemical yields and diasteresoselections of the two published examples with $\beta$-nitrostyrene $10\left(\mathrm{R}^{1}=\right.$ $\mathrm{Ph})$ were moderate $(53,57 \%$ and $63: 37 d r$, respectively) and the enantioselection was high in both cases $(96 \%$ ee) [53].

Polydentate brucine-derived (10) 26(Fig. 2) was initially used for the study of conjugate lition reaction of imino esters $\mathbf{6}$ onto nitroalkenes $\mathbf{1 0}$ giving selectively compounds anti-35 (Scheme 11a). The resulting nitroimines were cyclized employing DBU as base in DCM at room temperature because the direct 1,3-DC did not occur under these reaction conditions. Benzophenone imine $\mathbf{3 4}$ underwent the same Michael-type addition and only a change of the nature of solvent and base was enough to yield the corresponding cycloadduct endo-36 in the same reaction. Thus, when chiral complex 26. $\mathrm{CuCl}(10 \mathrm{~mol} \%)$, triethylamine (10 $\mathrm{mol} \%)$, ethanol as additive $(10 \mathrm{~mol} \%)$ and trichloroethylene as sol-

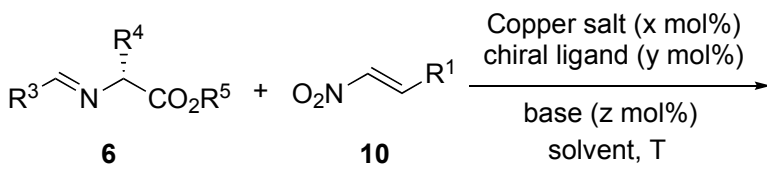

Scheme 7.
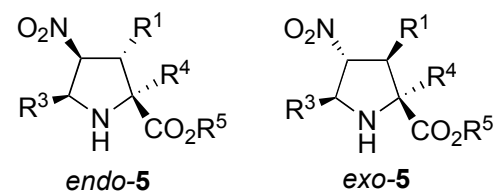
vent were used polysubstituted proline derivatives 36 were isolated in good yields (63-89\%), diastereoselections (up to $>99: 1$ ) and enantioselectivities (up to 94\% ee) (Scheme 11b). These results represented a clear demonstration of the stepwise nature of these 1,3-DC between nitroalkenes and metalloazomethine ylides [54].
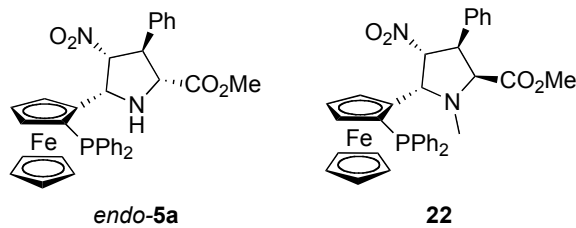

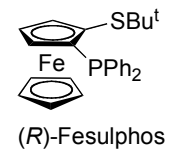

23

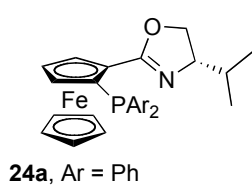

24b, $\mathrm{Ar}=3,5-\left(\mathrm{CF}_{3}\right)_{2} \mathrm{C}_{6} \mathrm{H}_{3}$

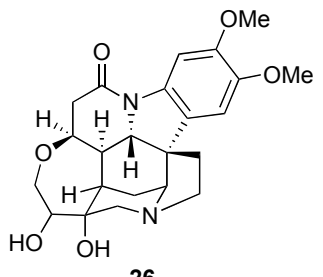

26

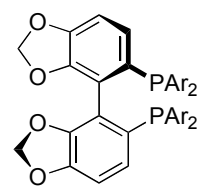

27a, $\mathrm{Ar}=\mathrm{Ph}$

27b, $\mathrm{Ar}=3,5-(\mathrm{Me})_{2} \mathrm{C}_{6} \mathrm{H}_{3}$ 27c, $\mathrm{Ar}=4-\mathrm{MeO}-3,5-\left(\mathrm{Bu}^{\mathrm{t}}\right)_{2} \mathrm{C}_{6} \mathrm{H}_{2}$

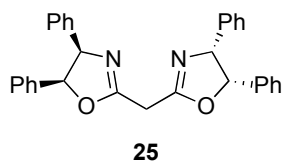

Fig. (2).

Segphos chiral ligand 27a and derivatives $27 \mathbf{b}$ and 27c (Fig. 2) were selected for the formation of chiral complexes with $\mathrm{Cu}(\mathrm{MeCN})_{4} \mathrm{PF}_{6}$ (only in a $1 \mathrm{~mol} \%$ loading) in the survey of the general scope of imino amides 37. Particularly, in the 1,3-D 37 and $\beta$-nitrostyrene only was effective complex 27a. $\left.2{ }^{2} \mathrm{NN}\right)_{4} \mathrm{PF}_{6}$. The diastereo- (up to $88: 12 d r$ ) and the enantioselectivity (up to $91 \%$ ee) were not so high than in precedent reactions, but the chemical yields of the major exo-stereoisomers 38 were high (80-87\%) (Scheme 12) $[55]$.

The same exo-diastereoselectivity was obtained during the synthesis of fluorinated proline derivatives 5. Catalytic system Walphos 28. $\mathrm{CuClO}_{4}(10 \mathrm{~mol} \%$ ) (Fig. 2), LiHMDS $(10 \mathrm{~mol} \%)$ in $\mathrm{DCM}$ at $0{ }^{\circ} \mathrm{C}$ were the optimum reaction conditions to perform the 1,3-DC of imino esters $6\left(\mathrm{R}^{3}=\mathrm{Ar}, \mathrm{R}^{4}\right.$ $\left.=\mathrm{H}, \mathrm{R}^{5}=\mathrm{Me}\right)$ with fluorinated nitroalkenes $\mathbf{1 0}\left(\mathrm{R}^{1}=\mathrm{CF}_{3}\right.$, $\mathrm{CF}_{2} \mathrm{H}, \mathrm{CF}_{2} \mathrm{Cl}, \mathrm{CF}_{2} \mathrm{Br}$ ) (Scheme 13). Cycloadduts exo-5 were isolated in moderate to good diastereoselections and yields (up to $27: 1$, and $47-88 \%$, respectively) and high enantioselectivities (up to 97\% ee) [56] (Scheme 13). The main goal of this methodology was the production of 4-amino-3(trifluoromethyl)proline, a molecule with potential biological activity, after reduction of the nitro functional group without epimerization.

The chiral ligands employed with more stable and easily handle copper(II) salts are depicte (Fig. 3). A couple of examples were recorded in the lit wire with different results in terms of diastereoselectivity. Thus, PyBidine 39 (Fig. 3), easily prepared by condensation of 2,4-pyridyldicarbaldehyde and $N$-benzyl $(S, S)$-diphenylethylenediamine, (5 mol\%) and copper(II) triflate (5 mol\%) formed a chiral complex able to promote the reaction showr (in Scheme 7) in the presence of 1,4-dioxane as solvent and carbonate or triethylamine as base $(10 \mathrm{~mol} \%)$. Unlike the other copper(I) and copper(II) chiral complexes, in which the general trend was the diastereoselective generation of exo-compounds, endo-cycloaducts 5 were selectively obtained (95:5 to $>99: 1$ $d r)$ in good yields (60-99\%) and excellent enantioselections (93-99\%). The authors justified these results on the basis of a concerted mechanism, where the negative charge of the nitro group interacted with the copper atom. This hypothesis was not confirmed for any theoretical study until date [57].

The title reaction has been catalyzed mainly with the combination of poly- or bidentate chiral ligands and copper(I) salts. Next, the unique example of monodentate chiral phosphoramidite ligand $\mathbf{4 0} \cdot \mathrm{Cu}(\mathrm{OTf})_{2}$ reported until now (Fig. 3) was exploited in the asymmetric synthesis of exo-prolines 5. The successful reaction conditions required $5 \mathrm{~mol} \%$ of catalyst loading, triethylamine $(10 \mathrm{~mol} \%)$, toluene and $25^{\circ} \mathrm{C}$. The resulting major e. $Q-$ iastereoisomers 5 were isolated in good exo/endo ratio (up wo 99:1), moderate to good chemical yields (44-79\%) and excellent enantioselections (up to $>99 \%$ $e e)$. In this contribution the effects of substituents of the nitroalkene $10\left(R^{1}\right)$, and substituents of the imino ester $6\left(R^{3}\right.$, $\mathrm{R}^{4}$, and $\mathrm{R}^{5}$ ) were evaluated together for the first time. Actually, dipole precursors derived from $\alpha$-substituted $\alpha$-amino acids such as leucine and phenylalanine afforded under the already described conditions compounds endo-5 in more than $99 \%$ ee. Such as occurred in precedent examples, here the experimental results of the reactions carried out at lower temperatures $\left(-80^{\circ} \mathrm{C}\right)$ giving also Michael adducts 41 supported the existence of a stepwise mechanism (Scheme 14)

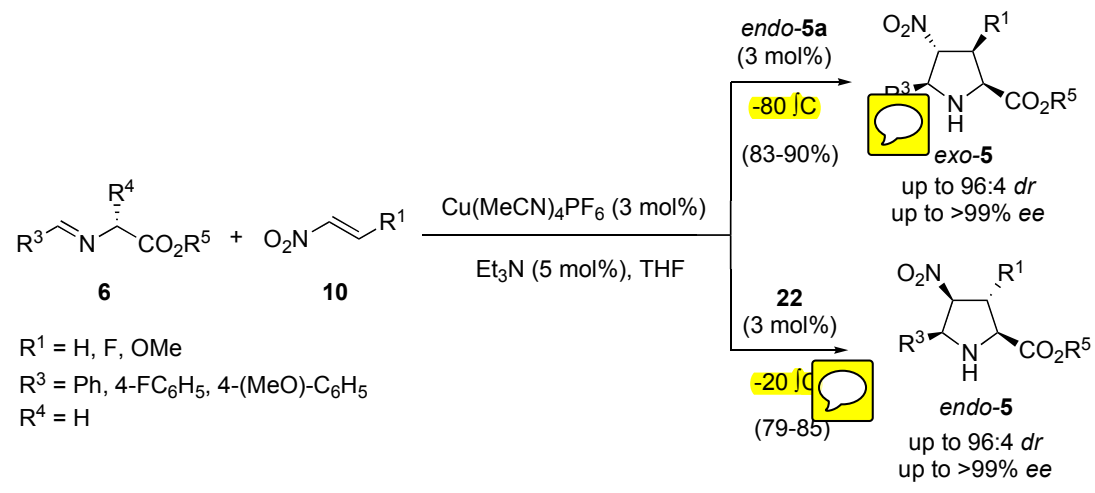

Scheme 8. 
[58]. The isolation of equimolecular quantities of exocycloadduct 5 and non-characterized syn-imine $\mathbf{4 1}$ followed by acidic work up allowed to obtain $\alpha$-amino ester $\mathbf{4 2}$ in $40 \%$ yield, 98:2 $d r$, and 94\% ee (Scheme 14).

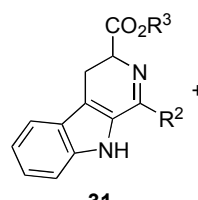

31

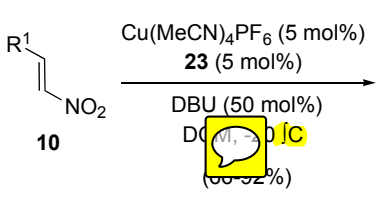

D?

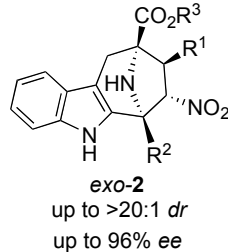

Scheme 9.
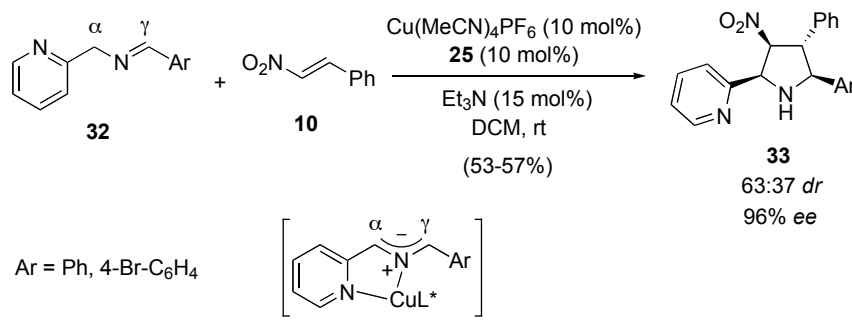

Scheme 10.

In addition, DFT calculations and parallel theoretical studies confirmed the low energy barrier for the previous transition state to the generation of this major exo-isomer 5 [59]. The mechanism of these metal catalyzed 1,3-DC can be exemplified by DFT calculations on the 30. $\mathrm{Cu}(\mathrm{OTf})_{2}$ catalyzed reaction to obtain exo-5 $\left(\mathrm{R}^{1}=\mathrm{Ph}, \mathrm{R}^{3}=\mathrm{Ph}, \mathrm{R}^{4}=\mathrm{H}, \mathrm{R}^{5}\right.$ $=\mathrm{Me})$. This model shown a single interaction Lewis acid imino ester 6 and that the coordination sphere of $\mathrm{Cu}(\mathrm{II})$ atom is saturated by an OTf moiety (note the importance of the anion to block the access of the nitroalkene). The most stable transition structures located are depicte (Fig. 4). Thus, exo-TS1 was found to be about $1.5 \mathrm{kcar}^{-1} \mathrm{~mol}^{-1}$ more stable than its enantiomeric counterpart. New carbon-carbon bond distances were very different to each other demonstrating the already mentioned asynchronous cyclization [59].

\subsection{Chiral Silver(I) and Gold(I) Complexes as Catalysts}

Chiral silver(I) complexes are very suitable for the control of the geometry of the 1,3-dipole furnishing mainly endo-cycloadducts. A large series of dipolarophiles have been successfully tested demonstrating the wide scope (higher than the analogous for the chiral copper-catalyzed cycloadditions) exhibited by the employment of this cation [60-70]. Despite the versatility shown by thes metal the employment of nitroalkenes 10 was very scarce (in Fig. 5) chiral ligands used in enantioselective silver(2, promoted 1,3-DC are illustrated.

Following the model reaction shown in (Scheme 15), chiral bipyrrolidine ligand 43(Fig. 5) and AgOTf (both in 5 mol\% loadings) promoted the reaction of imino ester $6\left(\mathrm{R}^{3}=\right.$ $\left.\mathrm{Ph}, \mathrm{R}^{4}=\mathrm{H}, \mathrm{R}^{5}=\mathrm{Me}\right)$ and $\beta$-nitrostyrene $\mathbf{1 0}\left(\mathrm{R}^{1}=\mathrm{Ph}\right)$ in the presence of potassium carbonate $(10 \mathrm{~mol} \%)$ in DCM at room temperature giving the $r 0$ ycloadduct5 as major isomer in modest results such as $43 \%$ yield, 1.8:1 $d r$ and $42 \%$ ee [71].

By contrast, ThioClickFerrophos 45 (5 mol\%), rather than ClickFerop 44(Fig. 5), as ligand and AgOAc as salt ( $5 \mathrm{~mol} \%$ ) gave a conplex that afforded the endo-cycloadduct 5 as major stereoisomer in poor yield (36\%), low diastereoselection $(65: 35 d r)$ and good enantioselectivity $(91 \% e e)$. The only difference with respect to the last example was the $\mathrm{R}^{3}$ substituent of the starting imino ester $6\left(4-\mathrm{ClC}_{6} \mathrm{H}_{4}\right.$ instead of $\mathrm{Ph}$ ) (Scheme 15) [72].

The same research group studied the reaction between benzophenone imine $\mathbf{3 4}$ and nitrostyrenes $\mathbf{1 0}\left(\mathrm{R}^{1}=\mathrm{Ar}\right.$, Scheme 11b). The ent-cycloadducts 36 were isolated as pure reaction product, 1 ith some impurities derived from Michael type addit compounds (up to 99:1 cycle:open chain), when the reactions were carried out at room temperature in THF in the absence of base and using ThioClickFerrophos 40.AgOAc chiral complex ( $5 \mathrm{~mol} \%)$. The enantioselectivities of compounds ent-36 were very high (up to 98\%) [73].

Privileged ligand Binap 46 (Fig. 5) was also evaluated as complex with silver(I) salts and with gold(I) salts. Whilst the reaction shown in (Scheme 15) completely failed in the presence of Binap 46. AgTfa ( Tfa $=\mathrm{CF}_{3} \mathrm{CO}_{2}^{-}, 5 \mathrm{~mol} \%$ ), the reaction of imino ester $6\left(\mathrm{R}^{3}=\mathrm{Ph}, \mathrm{R}^{4}=\mathrm{H}, \mathrm{R}^{5}=\mathrm{Me}\right)$ and $\beta$ nitrostyrene $10\left(\mathrm{R}^{1}=\mathrm{Ph}\right)$ using triethylamine $(10 \mathrm{~mol} \%)$ in toluene at room temperature catalyzed by dimeric $[(S)$-Binap 46. $\mathrm{AuTfa}_{2}$ (5 mol\%) gave compound exo-5 in 78\% yield, $80: 20$ diastereomeric ratio and $70 \%$ ee [74].
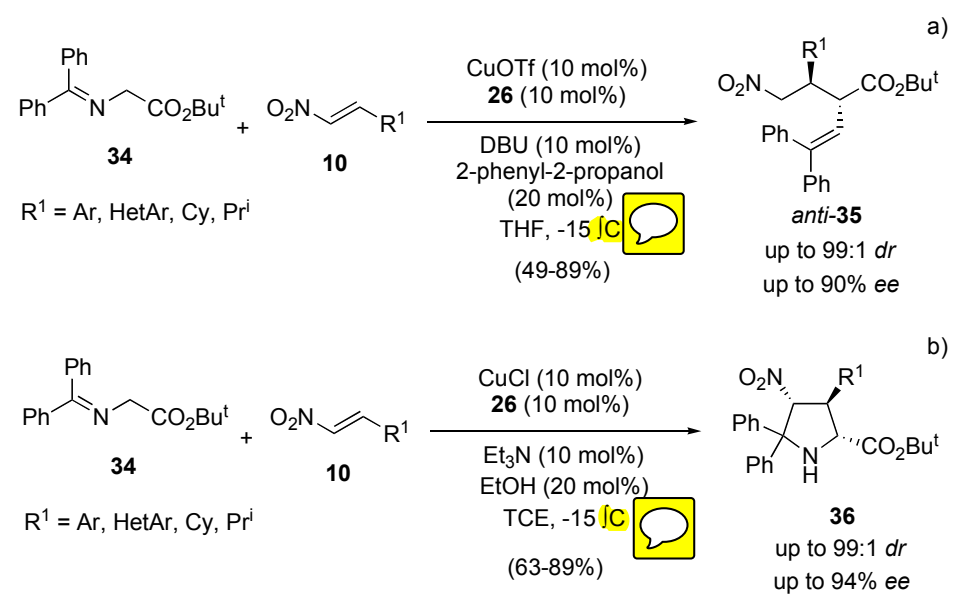

Scheme 11. 


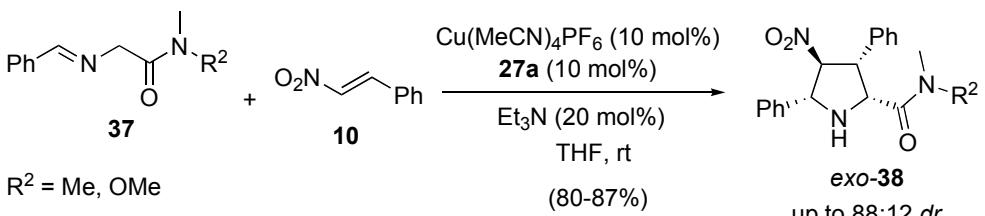

up to $88: 12 d r$

up to $91 \%$ ee

Scheme 12.
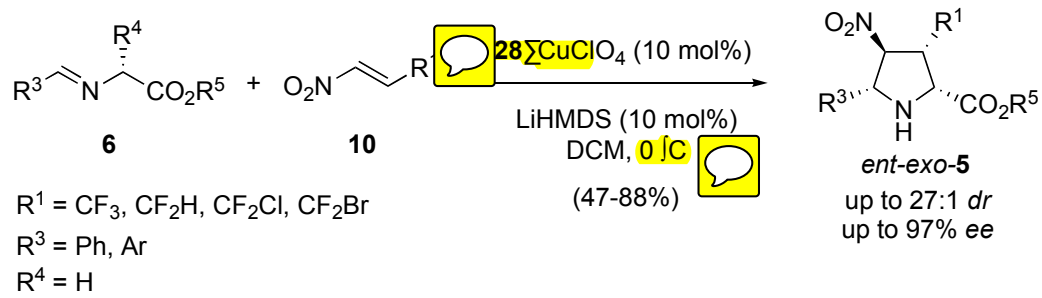

Scheme 13.
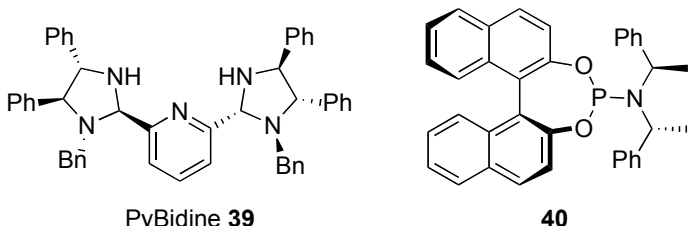

Fig. (3).

\subsection{Nickel Chiral Metal Complexes as Catalysts}

Another exo-selective 1,3-DC of imino esters with nitroalkenes has been described employing chiral ligand 47 (imidazoline-aminophenol scaffold, Fig. 6) together with $\mathrm{Ni}(\mathrm{OAc})_{2}$. The the the the lion of the screening of th action employing solid-phase supported imidazoline-aminophenol-( $\mathrm{NiOAc})_{2}$ catalysts. Only glycine derived imino esters $6\left(\mathrm{R}^{3}=\mathrm{Ar}, \mathrm{R}^{4}=\mathrm{H}, \mathrm{R}^{5}=\mathrm{Me}\right)$ and nitroalkenes $10\left(\mathrm{R}^{1}=\right.$ Ar or alkyl) were essayed using $10 \mathrm{~mol} \%$ of catalyst loading in the presence of potassium carbonate at $10{ }^{\circ} \mathrm{C}$ in acetonitrile as solvent. Non conventional exo'5 cycloadducts $\mathrm{No}$ obtained (corresponds with structure endo-5 epimer position, $\mathrm{R}^{3}$ is in trans-relative position with respect to the nitro group, Scheme 16) as major stereoisomers in good yields (64-99\%), with variable diastereoselectivity (two or three stereoisomers could be identified) and high enantioselections $(91-99 \%$ ee) [75].

\subsection{Chiral Organocatalysts}

Asymmetric organocatalysis is a topic of great interest due to the conceptual importance and environmentally benign feature [76-79]. However, to date, the number of reported examples about organocatalytic 1,3-DC is very low in comparison with all those involving chiral Lewis acids [8086]. Several chiral bifunctional organocatalysts bearing a tertiary amino group and a thiourea or a squaramide, able to form hydrogen bonding with the nitro group have been essayed (Fig. 7). The original structural limitations and inconveniences found with an organocatalyzed cycloaddition (only aminomalonate derived 1,3-dipoles were employed, or the large amount of the organocatalysts required, etc.) have been overcome with the incorporation of new organic catalysts.

The first organocatalytic enantio- and diastereoselective 1,3-dipolar cycloaddition of azomethine ylides and nitroalkenes occurred in the presence of the organocatalyst 48 (Fig. 7). The reaction of tert-butyl diphenylmethyleneaminoglycinate 34 and nitroalkenes $10\left(\mathrm{R}^{1}=\mathrm{Ar}\right.$, HetAr) was run in cyclohexane at $40{ }^{\circ} \mathrm{C}$ and a catalyst loading of $10 \mathrm{~mol} \%$ (Scheme 17). Under these particular conditions, products ent-36 were obtained as major stereoisomers (up to $>99: 1$ $d r)$, moderate to good yields (49-77\%) and moderate enantioselection $(46-65 \%$ ee) [87].

Thiourea 49 (Fig. 7) (10 mol\%) efficiently catalyzed the reaction of reactive imino esters 6 derived from diethyl aminomalonate $\left(\mathrm{R}^{3}=\mathrm{Ar}, \mathrm{R}^{4}=\mathrm{CO}_{2} \mathrm{Et}, \mathrm{R}^{5}=\mathrm{Et}\right)$ and nitroalkenes $10\left(\mathrm{R}^{1}=\mathrm{Ar}\right.$, HetAr) in toluene at $0{ }^{\circ} \mathrm{C}$. The presence of 2,2,2-trifluorethanol (TFE) as additive would activate the imino group after a weak protonation of the nitrogen atom increasing the reaction raterand conversions. The resulting polysubstitutedpyrrolidines (21) vere isolated between 52 and $86 \%$ yields, high diastereoselections (up to 98:2dr) (n) notable enantioselectivities (up to $92 \%$ ee) (Scheme 18) [oo].

A very interesting enantioselectively catalyzed multicomponent reaction successfully established a direct route to biologically important spiro[pyrrolidin-3,2'oxindole] scaffolds $\mathbf{5 4}$ (very similar to biologically active molecules $\mathbf{3}$, Fig. 1) with four contiguous stereogenic centers. Chiral squaramide 50 (5 mol\%, Fig. 7) in DCM at $40{ }^{\circ} \mathrm{C}$ allowed the 1,3DC of the in situ prepared imine from isatin derivative $\mathbf{5 2}$ and amine 53 with nitroalkenes $10\left(\mathrm{R}^{1}=\mathrm{Ph}, \mathrm{Ar}\right)$. Yields of spirocycle 54 were good (58-77\%) and also high diastereoselections (up to 10:1) and good enantiomeric excesses (up to $87 \%$ ee) were obtained (Scheme 19) [89]. A plausible explanation of the activation for this, and for the organocatalyzed cycloadditions described before, starts from the double hydrogen bonding of the diamide with nitro group. Nucleophile can be also activated through a second interaction with the quinuclidine nucleus. The approach can also be facilitated by a presumed $\pi$-stacking interaction according to II (Scheme 19). 


$$
\begin{aligned}
& \\
& \mathrm{R}^{1}=\mathrm{Ph} \\
& \mathrm{R}^{2}=\mathrm{Me} \\
& \mathrm{R}^{3}=\mathrm{Ph} \\
& \mathrm{R}^{4}=\mathrm{H}
\end{aligned}
$$$$
\mathrm{R}^{4}
$$$$
\mathrm{R}^{3}-\mathrm{CO}_{2} \mathrm{R}^{2}
$$$$
6
$$$$
\mathrm{R}^{1}=\text { Alkyl, Ph, Aryl }
$$$$
\mathrm{R}^{2}=\mathrm{Me}, \mathrm{Pr}
$$$$
\mathrm{R}^{3}=\mathrm{Ph}, \mathrm{Ar}
$$$$
\mathrm{R}^{4}=\mathrm{H}, \mathrm{Bu}^{\mathrm{i}}, \mathrm{Bn}
$$
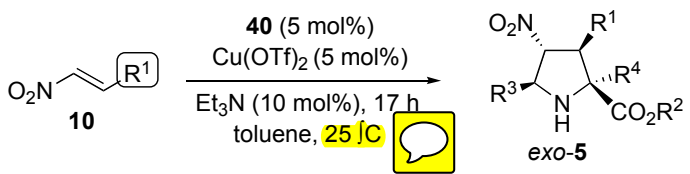<smiles>[R]OC1NC([R])C([N+](=O)[O-])C1[R]</smiles>

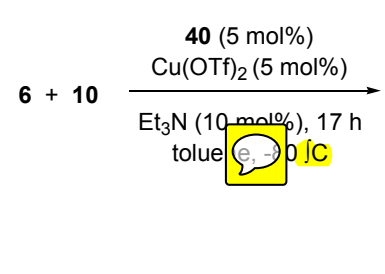

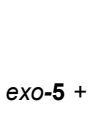

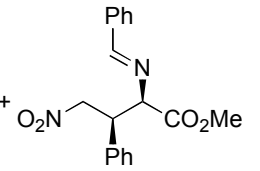

$1 \mathrm{MHCl}$
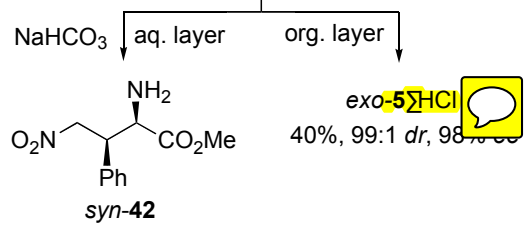

$40 \%, 98: 2 d r, 94 \%$ ee

\section{Scheme 14.}

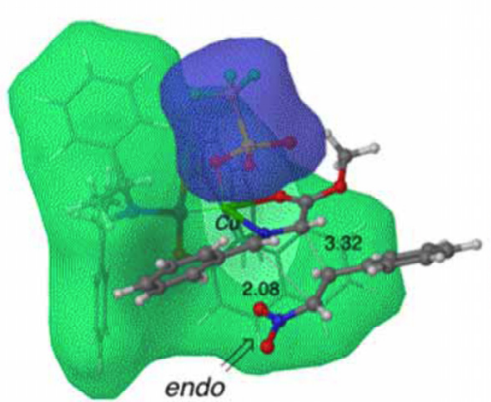

$(S, S)$-endo-TS1

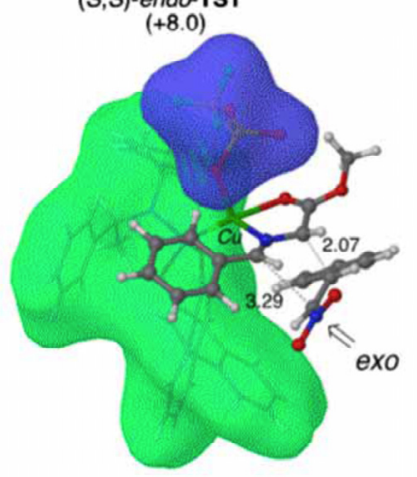

$(S, S)$-exo-TS1

(0.0)

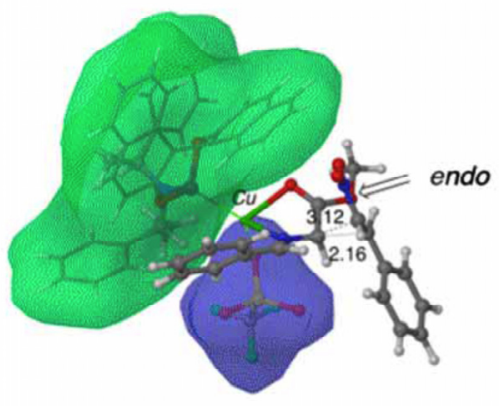

$(R, R)$-endo-TS1 $(+15.6)$

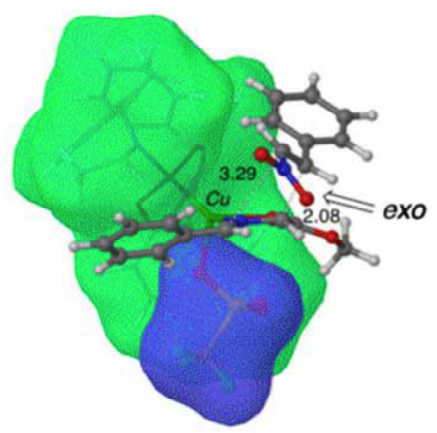

$(R, R) \cdot$ exo-TS1

$(+1.5)$
Fig. (4).

\section{CONCLUSIONS}

The increasing applications of nitro-substituted prolines in many scientific areas demand new and versatile methodologies to prepare them in optically enriched manner. Chiral metal complexes, acting as Lewis acids, are able to form the corresponding chiral metallodipole and induce high diastereoand enantioselectivities. Non-racemic copper(I) or (II) complexes favor, in general, the generation of the exocycloadducts although it has been published examples where a switchable or tunable ligands allow the formation of the endo- isomer. Another metal cations, such as silver(I), gold(I) and nickel(II) coordinated to chiral ligands represent a low number of examples in the literature with different diastereoselections between them. Recently, asymmetric organocatalysis have been applied to this 1,3-DC but did not improve the general scope and versatility of the already mentioned metal catalysis. The general mechanism of this cycloaddition is not concerted such as it has been demonstrated in many contributions but takes place in a sequential 1,4-Michael type addition followed by an intramolecular Mannich cyclization. 


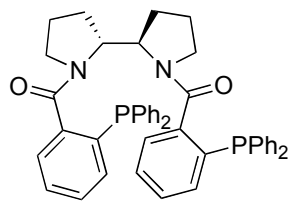

43

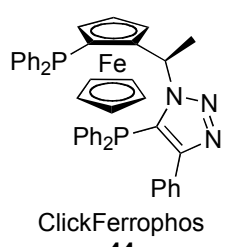

44

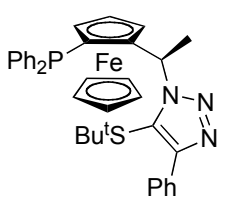

ThioClickFerrophos

45

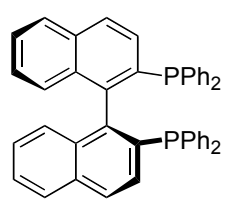

Binap 46

Fig. (5).
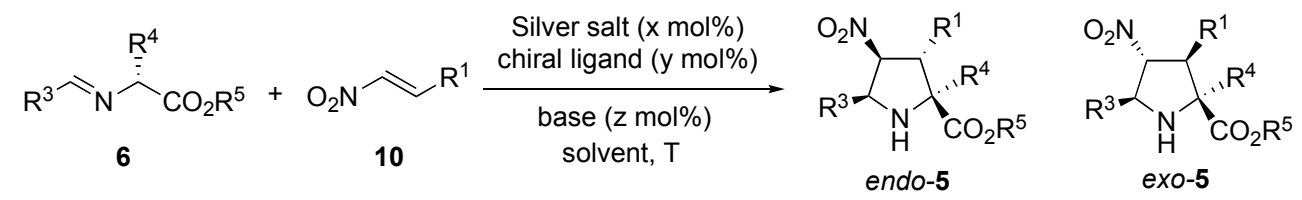

Scheme 15.<smiles></smiles>

47

Fig. (6).

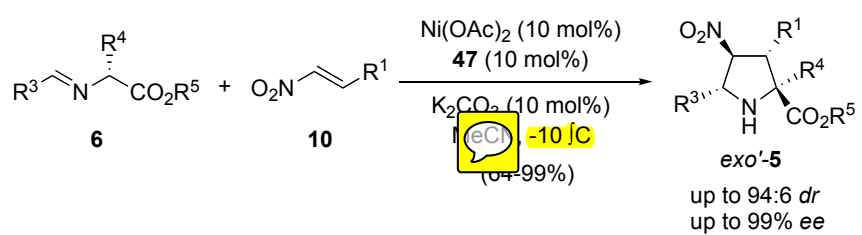

Scheme 16.<smiles>C=CC1CC2CCN1CC2C(NC(=S)Nc1cc(C(F)(F)F)cc(C(F)(F)F)c1)c1ccnc2ccc(OC)cc12</smiles><smiles>CN(C)C1CCCCC1NC(=S)Nc1cc(C(F)(F)F)cc(C(F)(F)F)c1</smiles>

48 49

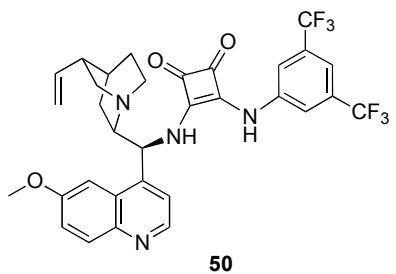

Fig. (7).

$$
\mathrm{R}^{1}=\mathrm{Ar} \text {, HetAr }
$$

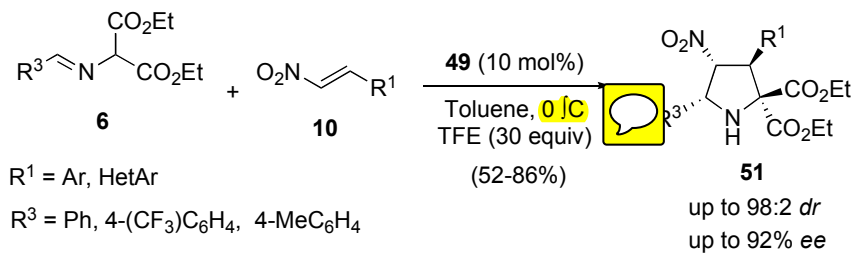

Scheme 18.
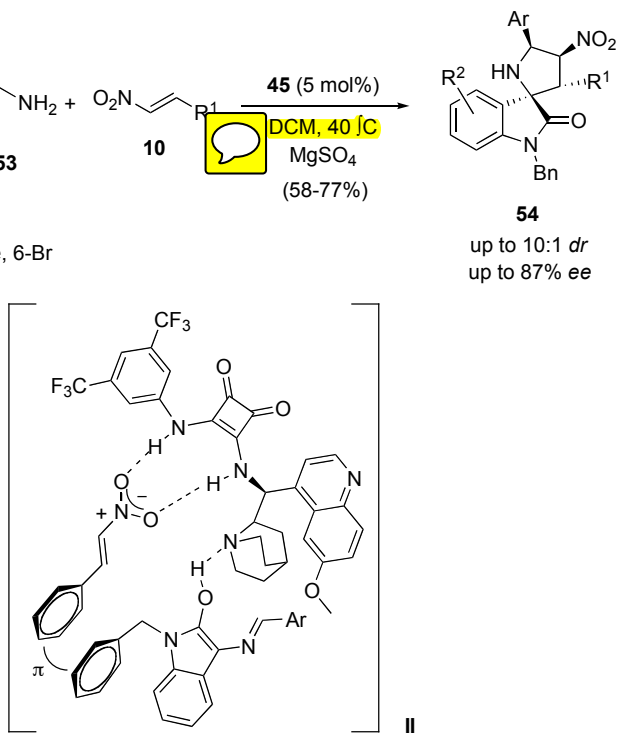

Scheme 19.

\section{CONFLICT OF INTEREST}

The author(s) confirm that this article content has no conflicts of interest.

\section{ACKNOWLEDGEMENTS}

This work has been supported by the Spanish Ministerio de Economía y Competitividad (MINECO) (Consolider INGENIO 2010 CSD2007-00006, CTQ2010-20387), FEDER, Generalitat Valenciana (PROMETEO/2009/039), and by the University of Alicante. 


\section{REFERENCES}

[1] Ono, N. The Nitro Group in Organic Synthesis, Wiley-VCH: New York, 2001

[2] El-Sayed, M.T.; Mahmoud, K.; Hilgeroth, A. Synthesis of $\beta$ Nitroamines via Classical Mannich and Aza-Henry Reactions. Curr. Org. Chem., 2013, 17, 1200-1225.

[3] Smith, D.J.; Anderson, R.C. Toxicity and Metabolism of Nitroalkanes and Substituted Nitroalkanes. J. Agric. Food Chem., 2013, 61, 763-779.

[4] San Sebastián, E.; Zimmerman, T.; Zubia, A.; Vara, Y.; Martin, E.; Sirockin, F.; Dejaegere, A.; Stote, R. H.; López, X.; Pantoja-Uceda, D.; Valcárcel, M.; Mendoza, L.; Vidal-Vanaclocha, F.; Cossío, F.P.; Blanco, F. J. Design, Synthesis, and Functional Evaluation of Leukocyte Function Associated Antigen-1 Antagonists in Early and Late Stages of Cancer Development. J. Med. Chem., 2013, 56, 735747.

[5] Zubia, A.; Mendoza, L.; Vivanco, S.; Aldaba, E.; Carrascal, T.; Lecea, B.; Arrieta, A.; Zimmerman, T.; Vidal-Vanaclocha, F.; Cossío, F.P. Application of Stereocontrolled Stepwise [3+2] Cycloadditions to the Preparation of Inhibitors of $\alpha_{4} \beta_{1}$-IntegrinMediated Hepatic Melanoma Metastasis. Angew. Chem. Int. Ed., 2005, 44, 2903-2907.

[6] Narayan, R.; Bauer, J.O.; Strohmann, C.; Antonchick, A.P.; Waldmann, H. Catalytic Enantioselective Synthesis of functionalized Tropanes Reveals Novel Inhibitors of Hedgehog Signaling. Angew. Chem. Int. Ed., 2013, 52, 12892-12896.

[7] Puerto-Galvis, C.E.; Kouznetsov, V.V. Regio- and Stereoselective Synthesis of Spiroxindole 1'-Nitro Pyrrolizidines with Five Concurrent Stereocentres Under Aqueous Medium and their Bioprospection Using the Zebrafish (Daniorerio) Embrio Model. Org. Biomol. Chem., 2013, 11, 7372-7386.

[8] Tripathi, R.P.; Bisht, S.S.; Pandey, V.P.; Pandey, S.K.; Singh, S.; Sinha, S.K.; Chaturvedi, V. Search of Antimycobacterial Activities in Hybrid Molecules with Benzopyran Skeleton. Med. Chem. Res., 2011, 20, 1515-1522.

[9] Conde, E.; Bello, D.; de Cózar, A.; Sánchez, M.; Vázquez, M.A.; Cossío, F.P. Densely Substituted Unnatural L- and D-Prolines as Catalysts for Highly Enantioselective Stereodivergent $(3+2) \mathrm{Cy}-$ cloadditions and Aldol Reactions. Chem. Sci., 2012, 3, 1486.

[10] Calaza, M.I.; Cativiela, C. Stereoselective Synthesis of Quaternary Proline Analogues. Eur. J. Org. Chem., 2008, 3427-3488.

[11] X. Companyó, A.N. Alba, R. Ríos, Targets in Heterocyclic Systems, vol 13, (Eds.: O. A. Attanasi, D. Spinelli), RSC, Cambridge 2009, pp. 147-185.

[12] Nájera, C.; Sansano, J.M. Proline and Pyrrolidine Derivatives. New Drug Candidates for Hepatitis C Treatme ActualitéChim.,
2013, 28-30.

[13] For recent reviews of asymmetric 1,3-DC, see ref. 13-20: Pellissier, H. Asymmetric 1,3-Dipolar Cycloadditions.Tetrahedron, 2007, 63, 3235-3285.

[14] Nájera, C.; Sansano J.M. Enantioselective Cycloadditions of Azomethine Ylides. In Topics in Heterocyclic Chemistry, A. Hassner, Ed. Springer-Verlag: Berlin-Heidelberg, 2008, vol. 12, pp. 117.

[15] Stanley, L.M.; Sibi, M.P. Enantioselective Copper-Catalyzed 1,3Dipoar Cycloadditions. Chem. Rev., 2008, 108, 2887-2902.

[16] Álvarez-Corral, M.; Muñoz-Dorado, M.; Rodríguez-García, I. Silver-Mediated synthesis of Heterocycles. Chem. Rev., 2008, 108, 3174-3198.

[17] Naodovic, M.; Yamamoto, H. Asymmetric Silver-Catalyzed Reactions. Chem. Rev., 2008, 108, 3132-3148.

[18] Nájera, C.; Sansano, J. M.; Yus, M. Metal Complexes versus Organocatalysts in Asymmetric 1,3-Dipolar Cycloadditions. J. Braz. Chem. Soc., 2010, 21, 377-412.

[19] Kissane, M.; Maguire, A. R. Asymmetric 1,3-Dipolar Cycloadditions of Acryl Amides. Chem. Soc. Rev., 2010, 39, 845-883.

[20] Adrio, J.; Carretero, J.C. Novel Dipolarophiles and Dipoles in the Metal-Catalyzed Enantioselective 1,3-Dipolar Cycloaddition of Azomethine Ylides. Chem. Commun., 2011, 47, 6784-6794.

[21] Synthetic Applications of 1,3-Dipolar Cycloaddition Chemistry Toward Heterocycles and Natural Products, (Eds. ndwa, W.H. Pearson), John Wiley \& Sons, New Jersey, 2003;

[22] Nájera, C.; Sansano, J.M. Azomethine Ylides in OYganmc Synthesis. Curr. Org. Chem., 2003, 7, 1105-1150.
[23] Eberbach, W. Advances in Cycloadditions. Sci. Synth., 2004, 27, chp. 11, 441-498.

[24] Coldham, I.; Hufton, R. Intramolecular Dipolar Cycloaddition Reactions of Azomethine Ylides. Chem. Rev., 2005, 105, 2765 2810 .

[25] Nair, V.; Suja, T.D. Intramolecular 1,3-Dipolar Cycloaddition Reactions in Targeted Synthesis. Tetrahedron, 2007, 63, 1224712275.

[26] Padwa, A.; Bur, S.K. The Domino Way to Heterocycles. Tetrahedron, 2007, 63, 5341-5378.

[27] Hashimoto, T.; Maruoka, K. Handbook of Cyclization Reactions, Ma, S. Ed. Wiley-VCH: Weinheim 2010.

[28] R. Grigg et al. pioneered the catalytic enantioselective 1,3-DC employing large amounts of chiral cobalt complexes. Allway, P.; Grigg, R. Chiral $\mathrm{Co}(\mathrm{II})$ and $\mathrm{Mn}(\mathrm{II})$ Catalysts for the 1,3-Dipolar Cycloaddition Reactions of Azomethine Ylides Derived from Arylidene Imines of Glycine. Tetrah rrol Lett.,1991, 32, 58175820 .

[29] Longmire. J.M.; Wang, B.; Zhang, X. Highly Enantioselective $\mathrm{Ag}(\mathrm{I})$-Catalyzed $[3+2]$ Cycloaddition of Azomethine Ylides. $J$. Am. Chem. Soc., 2002, 124, 13400-13401.

[30] Gothelf, A.S.; Gothelf, K.V.; Hazell, R.G.; Jørgensen, K.A. Catalytic Asymmetric 1,3-Dipolar Cycloaddition Reactions of Azomethine Ylides-A Simple Approach to Optically Active Highly Functionalized Proline Derivatives. Angew. Chem. Int. Ed., 2002, 41, 4236-4238

[31] The endo descriptor refers the approach of the dipolarophile in which the electron-withdrawing group of the 1,3-dipole and the nitro group are orientated in the same direction, whilst in the exodescriptor the corresponding groups are located in opposite direction.

[32] Arumugan, N.; Raghunathan, R. Synthesis of Highly Functionalized $\beta$-Lactam Substituted Pyrroloisoquinoline and Indolizinoindole System by Sequential Intermolecular 1,3-Dipolar Cycloaddition Reaction and Pictet-Spengler Cyclization. Tetrahedron, 2010, 66, 969-975.

[33] Huang, Y.; Li, Q.; Liu, T.-L.; Xu, P.-F. Diastereoselective Synthesis of $\beta$-Substituted- $\alpha, \gamma$-Diaminobutyric Acids and Pyrrolidines Containing Multichiral Centres. J. Org. Chem., 2009, 74, 12521258

[34] Ayerbe, M.; Arrieta, A.; Cossío, F.P.; Linden, A. Stereocontrolled synthesis of Highly Substituted Proline Esters via [3+2] Cycloaddition between $N$-Metalated Azomethine Ylides and Nitroalkenes. Origin of the Metal Effect on the Stereochemical Outcome. J. Org. Chem., 1998, 63, 1795-1805.

[35] Arrieta, A.; Otaegui, O.; Zubia, A.; Cossío, F.P.; Díaz-Ortíz, A.; de la Hoz, A.; Herrero, M.A.; Prieto, P.; Foces-Foces, C.; Pizarro, J.L.; Arriortua, M.I. Solvent-Free Thermal and MicrowaveAssisted [3+2] Cycloadditions between Stabilized Azomethine Ylides and Nitrostyrenes. An Experimental and Theoretical Study. J. Org. Chem., 2007, 72, 4313-4322.

[36] Grigg, R.; Kilner, C.; Sarker, M.A.B.; Orgaz de la Cierva, C.; Dondas, A. H. X=Y-ZH Compounds as Potential 1,3-Dipoles. Part 64: Synthesis of Highly Substituted Conformationally Restricted and Spiro Nitropyrrolidines via $\mathrm{Ag}^{\mathrm{I}}$ Catalysed Azomethine Ylide Cycloadditions. Tetrahedron, 2008, 64, 8974-8991.

[37] Nyerges, M.; Bitter, I.; Kádas, I.; Tóth, G.; Töke, L. 1,3-Dipolar Cycloaddition Approach Towards the Stereoselective Preparation of Aza-Cephalotaxine Skeleton. Tetrahedron Lett., 1994, 35, 44134414

[38] Fan, L.-P.; Yang, W.-J.; Xu, D.-C.; Li, X.-S.; Xie, J.-W. Efficient Methods for the Synthesis of Benzopyrano[3,4-c]pyrrolidines by Catalyzed 1,3-Dipolar Cycloaddition of Azomethine Ylides with 3Substituted Coumarins. Synth. Commun., 2011, 41, 3376-3384.

[39] Jia, J.; Du, D.-M. Catalyst-Free, One Pot Three-Component 1,3Dipolar Cycloaddition of Diethyl 2-Aminomalonate, Benzaldehydes and 3-Nitro-2H-Chromenes. RCS $A d v$., 2013, 3, 1970-1975.

[40] Aly, M.F.; Abbas-Temirek, H.H.; Elboray, E.E. Stereospecific Non-Decrboxylative 1,3-Dipolar Cycloaddition as a Potential Route to Proline Derivatives, Part III.

[41] Crovetto, L.; Ríos, R. One Pot, Three Component, Highly Diastereoselective Metal-Free Synthesis of 2,3,4,5-Tetrasubstituted Pyrrolidines. Synlett, 2 (0) 2008(12), 1840-1844.

[42] Korotaev, V.Y.; Bark .Y.; Moshkin, V.S.; Matochkina, E.G.; Kodess, M.L.; Sosnovskikh, V.Y. Highly Diastereoselective 1,3Dipolar Cycloaddition of Nonstabilized Azomethine Ylides to 3- 
nitro-2-trihalomethyl-2H-chromenes: Synthesis of 1Benzopyrano[3,4-c]pyrrolidines. Tetrahedron, 2013, 69, 86028608.

[43] For recent contributions see ref. 43-49. Potowski, M.; Bauer, J.O.; Strohmann, C.; Antonchick, A.P.; Waldmann, H. Highly Enantioselective Catalytic [6+3] Cycloadditions of Azomethine Ylides. Angew. Chem. Int. Ed., 2012, 51, 9512-9516.

[44] Wang, M.; Wang, C.-J.; Lin, Z. Cu(I)/TF-BiphamPhos Catalyzed Reactions of Alkylidene Bisphosphates and Alkylidenemalonates with Azomethine Ylides: Michael Addition versus 1,3-Dipolar Cycloaddition. Organometallics, 2012, 31, 7870-7876.

[45] Li, Q.-H.; Xue, Z.-Y.; Tao, H.-Y.; Wang, C.-J. Cu(I) DTBMBIPHEP-Catalyzed exo-Selective 1,3-Dipolar Cycloaddition of Azomethine Ylides with cis-Trifluorocrotonate for Asymmetric Construction of Trifluoromethylated Pyrrolidines. Tetrahedron Lett., 2012, 53, 3650-3653.

[46] Dingce, Y.; Qinghua, L.; Chunjiang, W. A Facile Access to Fluorinated Pyrrolidines via Catalytic Asymmetric 1,3-Dipolar Cycloaddition of Azomethine Ylides with Mehyl $\alpha$-Fluoroacrylate. Chin. J. Chem., 2012, 30, 2714-2720.

[47] He, Z.; Liu, T.; Tao, H.; Wang, C.-J. A Facile Access to Enantioenriched Isoindolines via One-Pot Sequential $\mathrm{Cu}(\mathrm{I})$-Catalyzed Asymmetric 1,3-Dipolar Cycloaddition/Aromatization. Org. Lett., 2012, 14, 6230-6233.

[48] Hernández-Toribio, J.; Padilla, S.; Adrio, J.; Carretero, J.C. Catalytic Asymmetric Synthesis of $\alpha$-Quaternary Proline Derivatives by 1,3-Dipolar Cycloaddition of $\alpha$-Silylimines. Angew. Chem. Int. Ed., 2012, 51, 8854-8858.

[49] He, Z.-L.; Teng, H.-L.; Wang, C.-J. Fulvenes as Effective Dipolarophiles in Copper(I)-Catalyzed [6+3] Cycloaddition of Azomethine Ylides: Asymmetric Construction of Piperidine Derivatives. Angew. Chem. Int. Ed., 2013, 52, 2934-2938.

[50] Cabrera, S.; Gómez-Arrayás, R.; Carretero, J.C. Highly Enantioselective Copper(I)-Fesulphos-Catalyzed 1,3-Dipolar Cycloaddition of Azomethine Ylides. J. Am. Chem. Soc., 2005, 127, 1639416395.

[51] Cabrera, S.; Gómez-Arrayás, R.; Martín-Matute, B.; Cossío, F.P.; Carretero, J.C. Cu${ }^{\mathrm{I}}$-Fesulphos Complexes: Eficient Chiral Catalysts for Asymmetric 1,3-Dipolar Cvcloaddition of Azomethine Ylides. Tetrahedron, 2007, 63, 658

[52] Yan, X.-X.; Peng, Q.; Zhar I, Zhang, K.; Hong, W.; Hou, X.L.; Wu, Y.-D. A Highly Enantio- and Diastereoselective CuCatalyzed 1,3-Dipolar Cycloaddition of Azomethine Ylides with Nitroalkenes. Angew. Chem. Int. Ed., 2006, 45, 1979-1983.

[53] Padilla, S.; Tejero, R.; Adrio, J.; Carretero, J.C. N-(2Pyridylmethyl)imines as Azomethine Ylide Precursors in Catalytic Asymmetric [3+2] Cycloadditions. Org. Lett., 2010, 12, 56085611.

[54] Kim, H.Y.; Li, J.-Y.; Kim, S.; Oh, K. Stereodivergency in Catalytic Asymmetric Conjugate Addition Reactions of Glycine (Ket)imines. J. Am. Chem. Soc., 2001, 133, 20750-20753.

[55] González-Esguevillas, M.; Adrio, J.; Carretero, J.C. Cu-Catalyzed Asymmetric [3+2] Cycloaddition of $\alpha$-Iminoamides with Activated Olefins. Chem. Commun., 2012, 48, 2149-2151.

[56] Li, Q.; Ding, C.-H.; Weissensteiner, W.; Hou, H.-L. Diastereo and Enantioselective Synthesis of Fluorinated Proline Derivatives via Copper(I)-Catalyzed Asymmetric 1,3-Dipolar Cycloaddition. Synthesis, 2012, 44, 265-271.

[57] Arai, T.; Mishiro, A.; Yokoyama, N.; Suzuki, K.; Sato, H. Chiral Pyridyl Bis(imidazolinine)-Cu(OTf) 2 : Catalytic Asymmetric EndoSelective [3+2] Cycloaddition of Imino Esters with Nitroalkenes. $J$. Am. Chem. Soc., 2010, 132, 5388-5339.

[58] For a review, see: de Cózar, A.; Cossío, F. P. Stereocontrolled (3+2) Cycloadditions Between Azomethine Ylides and Dipolarophiles: a Fruitful Interplay Between Theory and Experiment. Phys. Chem. Chem., 2011, 13, 10858-10868.

[59] Castelló, L.M.; Nájera, C.; Sansano, J.M.; Larrañaga, O.; de Cózar, A.; Cossío, F.P. Phosphoramidite-Cu(OTf) $)_{2}$ Complexes as Chiral Catalysts for 1,3-Dipolar Cycloaddition of Imino Esters and Nitroalkenes. Org. Lett., 2013, 15, 2902-2905.

[60] For recent contributions see ref. 60-65. Jing, X.; He, C.; Dong, D.; Yang, L.; Duan, C. Homochiral Crystallization of Metal-Organic Silver Frameworks: Asymmetric [3+2] Cycloaddition of an Azomethine Ylide. Angew. Chem. Int. Ed., 2012, 51, 10127-10131.

[61] Han, M.-L.; Wang, D.-Y.; Zeng, P.-W.; Zheng, Z.; Hu, X.-P. New Chiral Ferrocenyl P.,S-Ligands for highly Diastereo- and Enanti- oselective Ag(I)-Catalyzed [3+2] Cycloaddition of Azomethine Ylides. Tetrahedron Asymmetry, 2012, 23, 306-312.

[62] Mancebo-Aracil, J.; Martín-Rodríguez, M.; Nájera, C.; Sansano, J.M.; Costa, P.R.R.; Crizanto de Lima, E.; Dias, A.G. Binap-Silver Salts as Chiral Catalysts for the Enantioselective 1,3-Dipolar Cycloaddition of Azomethine Ylides and Alkenes. Tetrahedron Asymmetry, 2012, 23, 1596-1606.

[63] Wang, Z.; Luo, S.; Zhang, S.; Yang, W.-L.; Liu, Y.-Z.; Li, H.; Luo, X.; Deng, W.-P. Catalytic Asymmetric Construction of Quaternary $\alpha$-Amino Acid Containing Pyrrolidines through 1,3-Dipolar Cycloaddition of Azomethine Ylides to $\alpha$-Aminoacrylates. Chem. Eur. $J .$, 2013, 19, 6739-6745.

[64] González-Esguevillas, M.; Adrio, J.; Carretero, J.C. Enantioselective Synthesis of 4-Aminopyrrolidine-2,4-dicarboxylate Derivatives via Ag-Catalyzed Cycloaddition of Azomethine Ylides with Alkylidene Azlactones. Chem. Commun., 2013, 49, 4649-4651.

[65] Yamashita, Y.; Kobayashi, S. Metal Amides as the Simplest Acid/Base Catalysts for Stereoselective Carbon-Carbon BondForming Reactions. Chem. Eur. J., 2013, 19, 9420-9427.

[66] Martín-Rodríguez, M.; Nájera, C.; Sansano, J.M.; Costa, P.R.R.; Dias, A.G.; de Lima, E.C. Binap-AgSbF6 vs. Binap-AgClO4 Complexes as Catalysts for the Enantioselective 1,3-Dipolar Cycloaddition Reactions of Azomethine Ylides and Alkenes. Synlett, 2010 $2010(6), 920$.

[67] Nájera, C. 2 mosa, M.G.; Martín-Rodríguez, M.; Sansano, J.M.; de Cózar, A.; Cossío, F.P. Synthesis of Prolines by Enantioselective 1,3-Dipolar Cycloaddition of Azomethine Ylides and Alkenes Catalyzed by Chiral Phosphoramidite-Silver(I) Complexes. Eur. J. Org. Chem., 2009, 2009(32), 522634.

[68] Nájera, C.; Retamosa, M.G.; 2 ho, J.M.; de Cózar, A.; Cossío, F.P. Enantioselective Synthesis of Polysubstituted Prolines by Binap-silver-catalyzed 2 Dipolar Cycloadditions. Tetrahedron Asymmetry, 2008,19, 2 323.

[69] Nájera, C.; Retamosa, M.U., Sansano, J.M. Catalytic Enantioselective 1,3-Dipolar Cycloaddition Reactions of Azomethine Ylides and Alkenes by Using Phosphoramidite-Silver(I) Complexes. Angew. Chem. In. Ed., 2008, 49, 6055-6058.

[70] Nájera, C.; Retamosa, M.G.; Sansano, J.M. Recoverable (R)- and (S)-Binap-Ag(I) Complexes for the Enantioselective 1,3-Dipolar Cycloaddition Reaction of Azon thile Ylides.Org. Lett., 2007, 9, 4025-4028.

[71] Gu, X.; Xu, Z.-J.; Lo, V.K.-J.; Che, C.M. Asymmetric [3+2] Cycloaddition of Azomethine Ylides Catalyzed by Silver(I) Triflate with a Chiral Bipyrrolidine-Derived Phosphine Ligand. Synthesis, 2012, 44, 3307-3314.

[72] Shimizu, K.; Ogata, K.; Fukuzawa, S.-i. Ag/ThioClickFerophos Catalyzed Highly Enantioselective 1,3-Dipolar Cycloaddition of Azomethine Ylides with Alkenes. Tetrahedron Lett., 2010, 51, 5068-5070.

[73] Imae, K.; Konno, T.; Ogata, K.; Fukuzawa, S.i.Silver/THioClickFerrophos-Catalyzed Enantioselective Conjugate Addition and Cycloaddition of Glycine Imino Ester with Nitroalkenes. Org. Lett., 2012, 14, 4410-4413.

[74] Martín-Rodríguez, M.; Nájera, C.; Sansano, J.M.; de Cózar, A.; Cossío, F.P. Binap-Gold(I) versus Binap-Silver Trifuoroacetate Complexes as Catalysts in 1,3-Dipolar Cycloadditions of Azomethine Ylides. Chem. Eur. J., 2011, 17, 14224-14233.

[75] Arai, T.; Yokoyama, N.; Mishiro, A.; Sato, H. Catalytic Asymmetric exo'-Selective [3+2] Cycloaddition of Imino Esters with Nitroalkenes. Angew. Chem. Int. Ed., 2010, 49, 7895-7898.

[76] MacMillan, W.C. The Advent and Development of Organocatalysis. Nature, 2008, 455, 304-308.

[77] Jiang, H.; Jørgensen, K.A. A Simple Recipe for Sophisticated Cocktails: Organocatalytic One-Pot Reactions-Concept, Nomenclature and Future Perspectives. Angew. Chem. Int. Ed., 2011, 50, 8492-8509.

[78] Moyano, A.; Ríos, R. Asymmetric Organocatalytic Cyclization and Cycloaddition Reactions. Chem. Rev., 2011, 111, 4703-4832.

[79] Pellisier, H. Recent Developments in Asymmetric Organocatalytic Domino Reactions. Adv. Synth. Catal., 2012, 354, 237-294.

[80] For recent contributions see ref. 74-80. Reboredo, S.; Vicario, J.L.; Badía, D.; Carrillo, L.; Reyes, E. Complete 2,5-Diastereocintrol in the Organocatalytic Enantioselective [3+2] Cycloaddition of Enals with Azomethine Ylides Derived from $\alpha$-Iminocyanoacetates: Asymmetric Synthesis of Pyrrolidines with Four Stereocentres. Adv. Synth. Catal., 2001, 353,3307-3312. 
[81] Shi, F.; Tao, Z.-L. Luo, A.-W.; Tu, S.-J.; Gong, L.Z. ScaffoldInspired Enantioselective Synthesis of Biologically Important Spiro[pyrrolidin-3,2'-oxindoles] with Structural Diversity Through Catalytic Isatin-Derived 1,3-Dipolar Cycloadditions. Chem. Eur. J., 2012, 18, 6885-6894.

[82] Reboredo, S.; Reyes, E.; Vicario, J.L.; Badía, D.; Carrillo, L.; de Cózar, A.; Cossío, F.P. An Amine-Catalyzed Enantioselective [3+2] Cycloaddition of Azomethine Ylides and $\alpha, \beta$-Unsaturated Aldehydes: Applications and Mechanistic Implications. Chem. Eur. J., 2012, 18, 7179-7188.

[83] Taghizadeh, M.J.; Arvinnezhad, H.; Samadi, S.; Jadidi, K.; Javidan A.; Notash, B. Synthesis of New Enantiosmerically Pure Spirooxindolopyrrolizidines via a Three-Component Asymmetric 1,3Dipolar Cycloaddition Reaction of Azomethine Ylides derived from Isatin. Tetrahedron Lett., 2012, 53, 5148-5150.

[84] Wang, L.; Shi, X.-M.; Dong, W.-P.; Zhu, L.-P.; Wang, R. Efficient Construction of Highly Functionalized Spiro[ $\gamma$-butyrolactonepyrrolidin-3,3'-oxindole]tricyclic Skeletons via an Organocatalytic 1,3-Dipolar Cycloaddition. Chem. Commun., 2013, 49, 3458-3460.
[85] Shi, F., Xing, G.-J.; Tan, W.; Zhu, R.-Y.; Tu, S. Enantioselective Construction of 2,5-Dihydropyrrole Skeleton with Quaternary Stereogenic Center via Catalytic Asymmetric 1,3-Dipolar Cycloaddition Involving $\alpha$-Arylglycine Esters. Org. Biomol. Chem., 2013, $11,1492-1489$.

[86] Guo, C.; Song, J.; Gong, L.-Z. Biomimetic Asymmetric 1,3Dipolar Cycloaddition: Amino Acid Precursors in Biosynthesis Serve as Latent Azomethine Ylides. Org. Lett., 2013, 15, 26762679.

[87] Xue, M.-X.; Zhang, X.-M.; Gong, L.-Z. The First Organocatalytic Enantio- and Diastereoselective 1,3-Dipoalr Cyclaoddition of Azomethine Ylides and Nitroalkenes. Synlett, 2008, 5, 691-694.

[88] Xie, J.; Yoshida, K.; Takasu, K.; Takemoto, Y. Thiourea-Catalyzed Asymmetric Formal [3+2] Cycloaddition of Azomethine Ylides with Nitroolefins. Tetrahedron Lett., 2008, 49, 6910-6913.

[89] Tian, L.; Hu, X.-Q.; Li, Y.-H.; Xu, P.-F. Organocatalytic Asymmetric Multicomponent Cascade Reaction via 1,3-Proton Shift and [3+2] Cycloaddition: An Efficient Strategy for the Synthesis of Oxindole Derivatives. Chem. Commun., 2013, 49, 7213-7215. 